\title{
Characterization of Alternaria species causing dark leaf spot disease on cabbages grown in Limuru and Nyeri, Kenya
}

\author{
Ogada $\mathrm{AR}^{\mathbf{1}^{*}}$, Ezekiel $\mathrm{MN}^{1}$, Jonah $\mathrm{KB}^{2}$ and Amuka $\mathrm{O}^{3}$
}

\author{
${ }^{1}$ Department of Biochemistry, Microbiology and Biotechnology, Kenyatta University, P.O Box 43844-00100, Nairobi \\ Kenya \\ ${ }^{2}$ Department of Plant Science, Kenyatta University. P.O Box 43844-00100, Nairobi Kenya \\ ${ }^{3}$ Department of Applied Plant Science, Maseno University, Private Bag Maseno, Kenya
}

Ogada AR, Ezekiel MN, Jonah KB, Amuka O 2021 - Characterization of Alternaria species causing dark leaf spot disease on cabbages grown in Limuru and Nyeri, Kenya. Plant Pathology \& Quarantine 11(1), 23-33, Doi 10.5943/PPQ/11/1/4

\begin{abstract}
Alternaria species are necrotic plant pathogens, and the fungi cause dark spot disease to nearly 4000 plants on young seedling in a seedbed or at any age, this includes crucifers, ornamentals, fruits and some cereals. The infection on leaves and stem appear as dark brown or black spots that form concentric ring patterns as they enlarge. The objective of the study was to characterize Alternaria species causing dark leaf spot disease of cabbages (Brassica oleracea var. capitata) grown in Kenya. In the study, a total of 56 of fungi were isolated from cabbage leaves that showed typical symptoms of dark leaf disease of cabbage in Limuru and Nyeri, Kenya farms during September 2019. Being the first identification of Alternaria spp causing dark leave spot disease on cabbages in Kenya, eleven isolates were morphologically identified as Alternaria species by their colony, mycelium, conidiophore and conidia characteristic and confirmed by molecular analysis of internal transcribe spacer regions of 5.8S rDNA gene. The fungi gene sequences showed a similarity of $99 \%$ with genes of other Alternaria species isolated in some countries in the World. Isolate LM017, LM019a, NY021, NY003 and NY019 were grouped with A. brassicicola reference strains, while isolate LM009, NY005, NY004 and NY012 were grouped with $A$. brassicae strains, similarly isolate LM013 and LM008 were grouped with A. alternata and Alternaria spp. JF439433 strains respectively. Morphological features act as a primary way of identifying fungi, although not feasible since some fungi genus are morphologically related, consequently molecular method of identification was sufficient for accurate identification since it reveals multiple non-monophyletic genera among the Alternaria spp clusters and Alternaria complex.
\end{abstract}

Key words - Alternaria alternata - Alternaria brassicae - Alternaria brassicicola - Alternaria spp. - ITS

\section{Introduction}

The dark leaf spot is a common disease of cabbage caused by Alternaria species, and it affects many Solanaceae, Cucurbitaceae (Mangala et al. 2006) and Brassicaceae (Lawrence et al. 2008) family from different geographical regions. The examples of plants infested by the pathogen include broccoli, cauliflower, Brussels sprouts, kale, cereals and fruits (Pitt \& Hocking 1997). 
Rain-splashed or wind-blown spores spread the disease during the growing season (MacKinnon et al. 1999). The fungi affect all aerial parts of plants such as leaves, pods, seeds, fruits, and stems (Srivastava et al. 2004) where the phytotoxins it produces induces chlorosis. Initially, the Alternaria spp. incites leaf spots diseases which appears as a small dark-coloured spot and are either elliptical or circular with the pale brown or black lesion, surrounded by yellow halochlorotic tissues (Fig. 1). Later the spots increase gradually in diameter up to one centimetre in a concentric manner then coalesces to form patches on the leaves (Neeraj \& Verma 2010). In humid weather, dark conidiophores and conidia are visible and arranged in concentric rings (Fig. 1). In heavily affected plants, the disease causes defoliation (Walker 2010), that results in the death of above-ground tissues. This is occasioned by absorption of nutrients and break down of the dead tissue by the cell wall degrading enzymes (Ayongwa 2011).

Morphological characterization is a primary taxonomy method of identifying Alternaria species (Cho et al. 2001). According to Simmons (1995), the method is based on differences in morphology of the fungal conidia. Although this is a simple method, it does not enhance the ability to pick, recognize and illustrate the finer details that distinguish the different species. However, the use of the molecular method of identification is increasingly preferred as the most reliable, in that it reveals the most obscure difference between, even among the most closely related species.

The method has been employed to analyze rDNA genes and ITS regions of the genes because the genes in these sections are highly conserved. Besides, the ITS regions are variable among species, are of appropriate size, and therefore suitable for sequencing procedures. They are amenable to PCR amplification and restriction analysis. Therefore, rDNA internal transcribed spacer regions (ITS1 and ITS2) are used in the establishment of species-level relationship (Samuels \& Seifert 1995), suitable for systematic and taxonomic classification of Alternaria species (Chillali et al. 1998).

\section{Materials \& methods}

\section{Isolation of Alternaria spp from infected cabbage leaves}

The cabbages showing typical symptoms of the dark leaf spot diseases caused by Alternaria spp. were selected from different farms in Limuru and Nyeri, Kenya (Fig. 1). Samples of infected leaves were collected (Fig. 1). The infected portions of leaves showing the black spot symptoms were chopped into smaller pieces and surface sterilized in $2 \%(\mathrm{v} / \mathrm{v})$ sodium hypochlorite solution for $3 \mathrm{~min}$, then washed five times with sterile water, in five aseptic glass plates. Segments of leaves with necrotic lesions and fresh parts were cut into four potions then placed on sterilized disposable Petri dishes that contains PDA under aseptic conditions, sealed with parafilm and kept in the dark at room temperature for 12 days with periodical observation for the fungal growth and to ensure there is no contamination.

\section{Purification of Alternaria isolates}

Measurement of $5 \mathrm{ml}$ of sterilized distilled water was added onto 12 days old cultures and shaken gently to dislodge spores from the mycelium. Two $\mathrm{ml}$ of the spore suspension were spread on the agar plates and incubated at $28^{\circ} \mathrm{C}$ for one day. Using a sterilized needle, a single germinated conidium was relocated by the help of microscope $\times 40$ from the culture to the new Petri dishes that hold fresh PDA and incubated at room temperature for four days. The periphery of actively growing mycelial colony of the culture was cut under aseptic conditions using $2 \mathrm{~mm}$ cork borer and sub-culture on PDA plates at room temperature for 12 days. The grown conidia were released from the mycelium by saturating universal bottle with $250 \mathrm{ml}$ disinfected sterile water then agitated gently by shaking and sieving using a sterilized muslin cloth, spores obtained were suspended in $10 \%$ glycerol and stored at $-70^{\circ} \mathrm{C}$ for further studies.

\section{Morphological identification of Alternaria spp.}

After 12 days of incubation, the mycelium, conidiophore and conidia morphology of each 
isolate was observed under X40 Leica DM 500 microscope (Leica, Germany) fitted with ICC505711411 camera and photographed on day 4, 8 and 12. The morphological characteristic used were; colony colour, texture, septation, zonation, margin, type of growth and shape.

\section{Molecular identification of Alternaria species.}

\section{DNA extraction}

DNA was extracted from the fungal isolate using the CTAB method (Gontia-mishra et al. 2014). An approximately $200 \mathrm{mg}$ of 12 days old mycelium of each Alternaria isolates grown on PDA were harvested using a sterile wire loop and placed on top of sterile glass beads milling for five (5) minutes, washed with $100 \mu \mathrm{TE}(\mathrm{pH}$ 8). Eight hundred microliters $(800 \mu \mathrm{l})$ of extraction buffer $(2.5 \mathrm{M} \mathrm{NaCl}, 10 \mathrm{mM}$ EDTA pH 8, $0.1 \mathrm{M}$ Tris-HCl pH 8, $150 \mu \mathrm{L}$ of $20 \mathrm{mg} / \mathrm{mL}$ proteinase K, $3.5 \%$ CTAB) was added to the lysate cell, vortexed for thirty seconds, $300 \mu 1$ of chloroform-isoamyl alcohol was added then the mixture formed was inverted until a white suspension was formed to get rid of proteins and cell debris. The solution formed were centrifuged (Eppendorf Centrifuge 5415D, Westburg, New York) at a low-slung speed of 13,000 rpm for 15 minutes and the supernatant was purified further according to manufacturer's procedure then transferred to 2.0ml Eppendorf tubes.

The extracted DNA was precipitated using three hundred microliters of $100 \%$ ethanol and kept in an incubator at $-20^{\circ} \mathrm{C}$ for half an hour. The DNA pellets were obtained by discarding the supernatant after centrifuging for 15 minutes at 13,000 for 15 minutes (Shiro et al. 2013). The pellets were dried at $28^{\circ} \mathrm{C}$ and re-dissolved in $30 \mu 1$ of water for molecular biology DNA/DNAse/RNAse free water. A total of between 70-150 mg of DNA from mycelium of each isolate was successfully extracted using ZR D 6005 Quick DNA Fungal/bacterial MinPrep Kit (Zymo Research, South Africa) and detected using gel electrophoresis, then kept at $-20^{\circ} \mathrm{C}$ after been washed out in sterile purified water.

\section{Polymerase chain reaction (PCR) amplification}

The PCR amplification of the 5.8S rDNA gene containing the ITS (internal transcribed spacer) regions from each Alternaria isolates was performed using a Progene Thermal Cycler (Techne Ltd, UK). $50 \mu \mathrm{L}$ mixture contains; $25 \mu \mathrm{L}$ Master mix, $1.0 \mu \mathrm{M}$ of each ITS1 forward primer (5'-AAC TCC CAA ACC CCT GTG AAC ATA -3') and ITS4 reverse primer (5'-TTT AAC GGC GTG GCC GC $-3^{\prime}$ ) respectively, $23 \mu \mathrm{L}$ of nuclease-free water and $1.0 \mu \mathrm{g}$ of DNA template. The PCR reactions were performed for 35 cycles as follows; denaturation at $95^{\circ} \mathrm{C}$ for 35 cycles in 5 minutes, each cycle for 30 seconds at $94^{\circ} \mathrm{C}, 30$ seconds at $52^{\circ} \mathrm{C}, 1$ minute at $72^{\circ} \mathrm{C}$ and 10 minutes at $72^{\circ} \mathrm{C}$ for final extension (Kwasna \& Bateman 2007).

\section{Agarose gel electrophoresis}

Five (5) microliters of amplified PCR products were stained with SYBR green and separated by gel electrophoresis in $1.4 \%(\mathrm{w} / \mathrm{v})$ agarose gel in Tris-Acetate-EDTA $(0.5 \times \mathrm{TAE})$ and run at $80 \mathrm{~V}$ for one hour. A molecular marker of one hundred base pair (100 bp DNA ladder) was used to approximate the molecular weight and size of the bands. Finally, the bands were visualized with U.V trans-illuminator lamp and photographed (Kwasna \& Bateman 2007) using a Sony 14.1 megapixel digital camera.

\section{DNA sequencing and analysis}

Before sequencing, the PCR products samples were purified using the enzymatic purification method, then sequenced using the ABI 3730xI DNA Analyzer. Sequencing reactions were carried out in the DNA Master cycler pro 384 (Eppendorf) using the ABI BigDye $\AA$ Terminator v3.1 Cycle Sequencing Kit (Applied Biosystems), following the protocols supplied by the manufacturer. Single-pass sequencing was performed on each template using universal primers ITS 4 and ITS 1, with a mixture of $20 \mu \mathrm{L}$ which contains; $2.0 \mu \mathrm{L}$ BigDye, $3 \mu \mathrm{L}$ DNA, $1.5 \mu \mathrm{L}$ of each reverse and forward primers (ITS 4 and ITS 1), $10.5 \mu \mathrm{L}$ disinfected water and $1.5 \mu \mathrm{L} 5 \mathrm{x}$ sequence buffer, 
(Kwasna \& Bateman 2007). The mixture was taken to a PCR machine DNA master cycler pro 384 (Eppendorf) thermocycler and performed as per the following condition; denaturation at $96^{\circ} \mathrm{C}$ for 5 minutes, for 10 seconds at $96^{\circ} \mathrm{C}$, annealing at $50^{\circ} \mathrm{C}$ for 5 seconds then at $60^{\circ} \mathrm{C}$ for 4 minutes extension (Tamura et al. 2004)). The fluorescent-labeled fragments were purified from the unincorporated terminators with the BigDye XTerminator ${ }^{\circledR}$ Purification Kit (Applied Biosystems).

The sequences of the PCR products were aligned by CLUSTAL-W through MEGA X version 10.05 software (Khalse et al. 2017) and edited by DNA baser assemble (Version 5,15.0) software. The homologies to the sequence data were searched using remote BLAST service of the NCBI (National Center for Biotechnology Information). The evolutionary history was inferred by using the maximum likelihood method and Kimura 2-parameter model (Kimura 1980) while the analyses were conducted in MEGA $X$ version 10.0.5 (Kumar et al. 2018). The phylogenetic tree was obtained by applying Neighbor-join and BioNj algorithms to a matrix of pairwise distances estimated using the Maximum Composite Likelihood (MCL) approach at 1000 bootstrap replicates.

\section{Results}

\section{Morphological characteristic of Alternaria isolate}

The mycelium of the fungus grew slowly either creeping or appearing raised and fluffy raised on PDA, producing regular to irregular colony with a smooth white margin (Fig. 2 ). Isolate 008, 013, 017, 019a, 021 and 003 were regular while 009, 019, 005, 004 and 012 were irregular.The colony textures were either cottony (isolate 009, 008, 013, 017, 005, 004 and 012) or powdery (Table 1) (isolate 019a, 019, 021 and 009).

Most of the colony colour of the isolates were brown, grey to either light grey or olivaceous grey.The dark green under-surface was observed in isolate 009, 008, 021, 005 and 012; brown was observed in isolate 017, 019a, 003 and 019 while dark brown and green was observed in isolate 004 and 013 respectively. The results are in agreement with Muthukumar \& Venkatesh (2013), the colony colour of $A$. alternata isolated from ribben plant was black to olivaceous black or grey on PDA medium. The colony colour of 32 isolates observed by Deep et al. (2014) varied from dark olivaceous black to olive green. In this study the colony of the isolates had velvety or cottony texture on PDA medium, the result conformed with the study done by Pryor \& Michailides (2002). They examined 308 Alternaria species and found out that group 4 had a cottony texture. According to Sofi et al. (2013), a colony of Alternaria mali the causal organism of Alternaria blotch varied from cottony to velvety these also supports the results of the study.

The mycelium colour was either grey, light grey to oliverous grey or brown (Fig. 3A), isolate 009 and 013 was grey, isolate 008, 019a and 019 was light grey, isolate 017, 005 and 012 was oliverous grey while isolate 021,003 and 004 were brown on the front of the plate (Table 1) while on the undersurface of the cultures. The results are in agreement with Muthukumar \& Venkatesh (2013). They isolated A. alternata from ribben plant and found out that its colony colour was black to olivaceous black or grey on PDA medium. On both front and under the surface of the culture of each isolate, there were distinct circular zonations of either black or brown rings (Fig. 2, Table 1).

\section{Conidiophore and conidia characteristic}

There was a morphological variation of conidiophore in terms of colour, shape, formation of chains, septation of eleven Alternaria spp. cultured on PDA medium. The conidiophores were branched, septate, and the colour varied from brown, deep brown to light brown when stained with lactophenol (Table 1, Fig. 3B), similar characteristics were noted by Cho et al. (2001) on different Alternaria spp. Isolate 005 and 008 their conidiophores were brown, isolates 009, 013, 017, 003 019a and 019 was light brown whereas isolate 021,004 and 012 showed dark brown conidiophores (Table 1).

The conidia of the cultures were all septate, which consist of between 2-7 cells (Fig. 3C). Some were muriform and produced in single or in a long chain (Table 1, Fig. 3D). The finding was also similar to previous results by Ellis (1971), who describe A. brassicicola conidiophores as 
septate, olivaceous, branched, the conidia as dark, oblong to cylindrical and muriform. Kumar et al. (2014) and some mycological researcher working with Alternaria spp found brownish black, obclavate and muriform conidia.

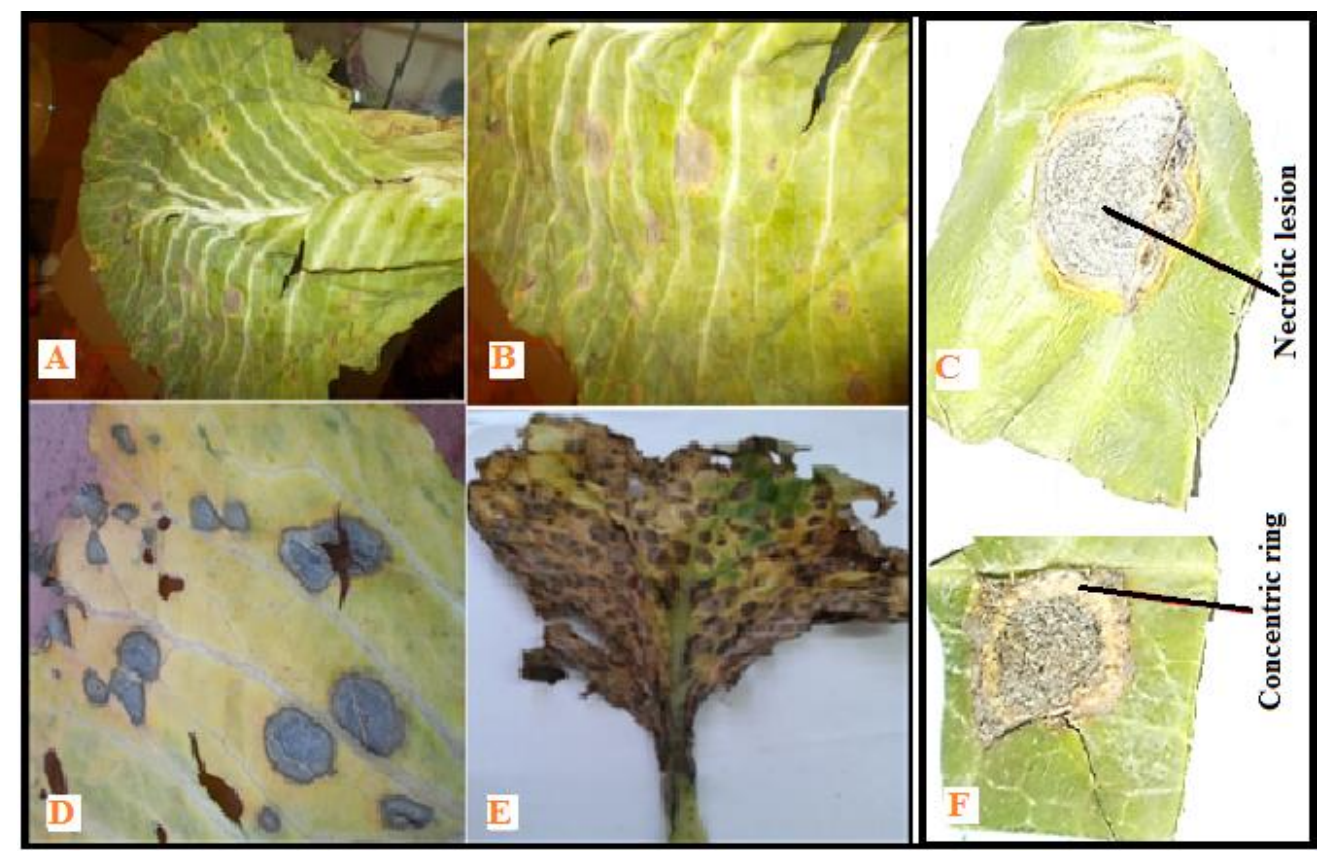

Fig. 1 - Symptoms of black leaf spot diseases caused by Alternaria spp on cabbages leaves sampled from Kenya farms. The infected portions of cabbage leaves ( $\mathrm{C}$ and $\mathrm{F}$ ) showing typical symptoms of black spot disease caused by A. brassicicola. The concentric rings and necrotic lesion are shown on the figure. A a black spots. B circular spots with black concentric rings. D enlarged black spots. E severe A. brassicicola infection on cabbage leaf.

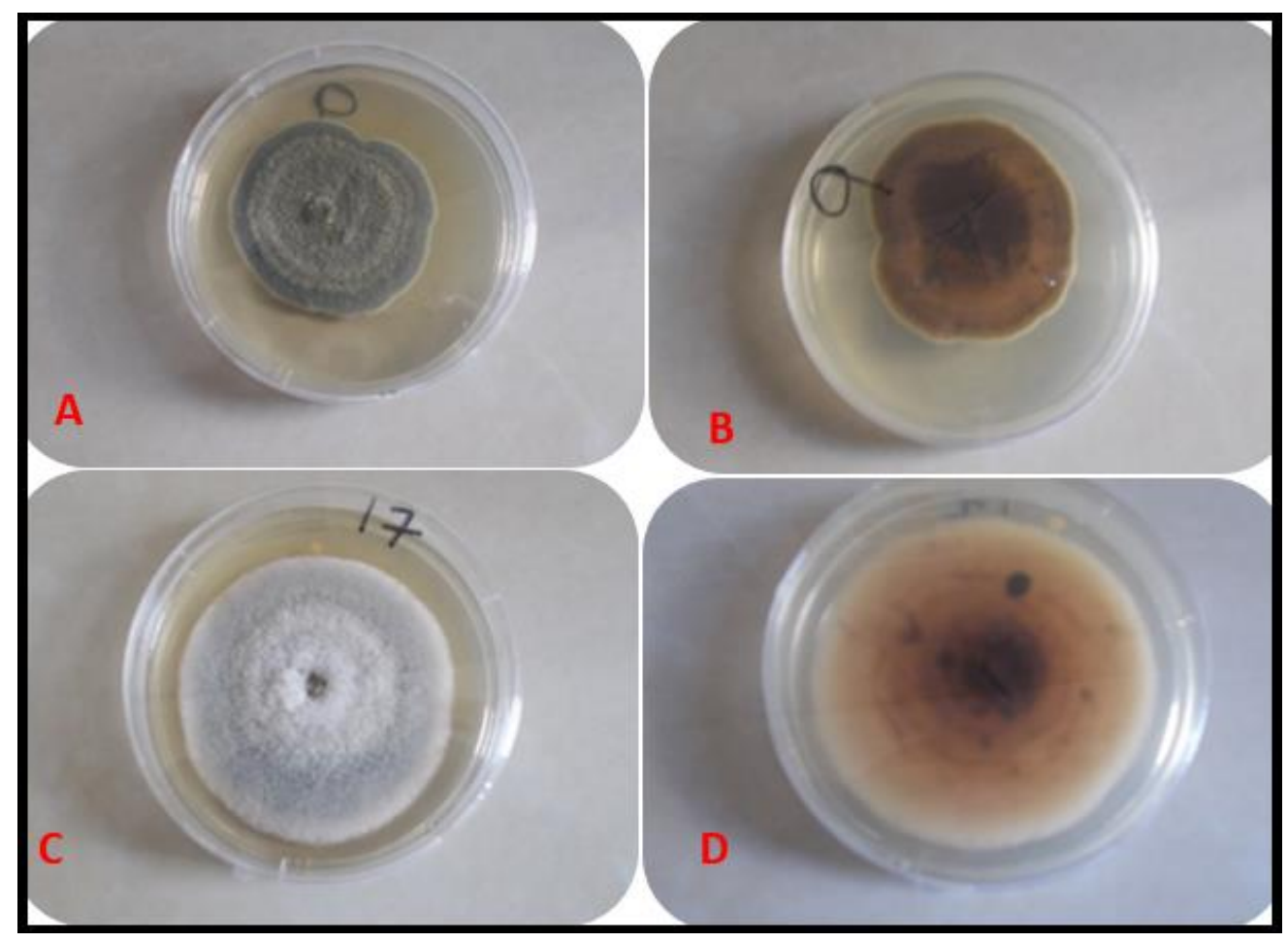

Fig. 2 - Colony of selected Alternaria spp. cultured on PDA plate $8^{\text {th }}$ day after inoculation. A Front view of isolate LM009. B Under the surface view of isolate LM009. C Front view of isolate LM017. D Under the surface view of isolate NY005. 


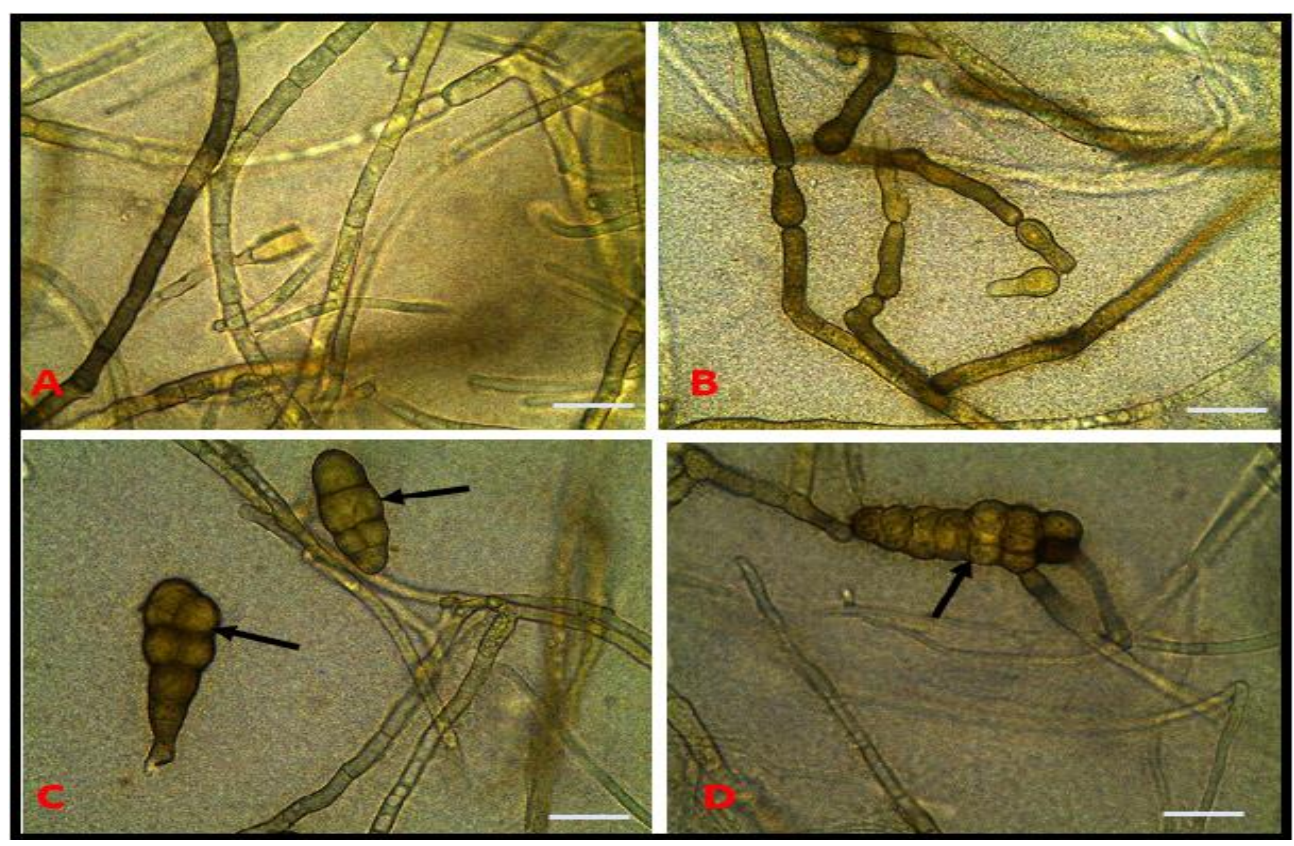

Fig. 3 - Morphological characteristic of selected Alternaria isolates. A Septate mycelium of isolate LM009. B Septate conidiophore of isolate NY012. C Septate conidium of isolate NY004. D Moriform conidia of isolate LM017. Black arrows show septation of conidia. Scale bar: $0.3 \mathrm{~mm}$.

Vertical septation varied from 1-3 to 5-7, while horizontal septation varied from 0-2 to 2-8. These results are partially supported by Saha et al. (2016), who isolated 23 A. brassicae and found 8-9 transverse and two vertical septations. Monowara et al. (2017), observed 10 A. brassicae with 3-7 to 7-11 horizontal and 0-1 to 2-3 vertical septa conidia. The minimum vertical septation was observed in isolate $009,012,013$ and 019 while the maximum vertical septation observed in isolate 017 and 005 (Table 1). The minimum horizontal septation was observed in isolate 008, 013, 003, 019, 019a, 005 and 012 while the maximum horizontal septation was observed in isolate 017, 021, 009 and 004 (Table 1). According to Sofi et al. (2013) findings, the horizontal septation of five A. brassicae isolates varied from 4-13 and vertical septa varied from 0-6. Ten isolates of $A$. macrospora were found to have 1-6 transverse and 0-4 longitudinal septa (Jadhav et al. 2011).

Table 1 Morphological characteristic of Alternaria spp. isolated from infected cabbage leaves in Limuru and Nyeri

\begin{tabular}{|c|c|c|c|c|c|c|c|c|c|c|c|}
\hline \multirow{2}{*}{ Characteristics } & \multicolumn{11}{|c|}{ Isolate codes } \\
\hline & 009 & 008 & 013 & 017 & $019 a$ & 021 & 003 & 019 & 005 & 004 & 012 \\
\hline \multicolumn{12}{|l|}{ Colony } \\
\hline Shape & IR & $\mathrm{R}$ & $\mathrm{R}$ & $\mathrm{R}$ & $\mathrm{R}$ & $\mathrm{R}$ & $\mathrm{R}$ & IR & IR & IR & IR \\
\hline Growth & $\mathrm{F}$ & $\mathrm{F}$ & $\mathrm{F}$ & $\mathrm{F}$ & Fy & $\mathrm{F}$ & $\mathrm{F}$ & $\mathrm{F}$ & $\mathrm{F}$ & $\mathrm{F}$ & $\mathrm{F}$ \\
\hline Texture & $\mathrm{C}$ & $\mathrm{C}$ & $\mathrm{C}$ & $\mathrm{C}$ & $\mathrm{P}$ & $\mathrm{P}$ & $\mathrm{P}$ & $\mathrm{P}$ & $\mathrm{C}$ & $\mathrm{C}$ & $\mathrm{C}$ \\
\hline Margin & WS & WS & WS & WS & WS & BS & WS & BS & WS & WS & WS \\
\hline Front & $\mathrm{G}$ & LG & $\mathrm{G}$ & OG & LG & B & $\mathrm{B}$ & $\mathrm{LG}$ & OG & $\mathrm{B}$ & OG \\
\hline Center & DG & B & B & DB & DB & G & $\mathrm{O}$ & $\mathrm{B}$ & $\mathrm{B}$ & $\mathrm{DB}$ & B \\
\hline Reverse & $\mathrm{Dg}$ & $\mathrm{Dg}$ & $\mathrm{G}$ & $\mathrm{B}$ & B & $\mathrm{Dg}$ & $\mathrm{B}$ & B & Dg & DB & $\mathrm{Dg}$ \\
\hline Zonation & Cbr & $\mathrm{Cbr}$ & $\mathrm{Cbr}$ & $\mathrm{CBr}$ & $\mathrm{Cbr}$ & Cbr & $\mathrm{CBr}$ & Cbr & $\mathrm{Cbr}$ & $\mathrm{CBr}$ & $\mathrm{Cbr}$ \\
\hline \multicolumn{12}{|l|}{ Conidiophore } \\
\hline Color & LB & B & LB & LB & LB & DB & LB & LB & B & $\mathrm{DB}$ & DB \\
\hline Septation & Sep & Sep & Sep & Sep & Sep & Sep & Sep & Sep & Sep & Sep & Sep \\
\hline Branched & $\mathrm{Br}$ & $\mathrm{Br}$ & $\mathrm{Br}$ & $\mathrm{Br}$ & $\mathrm{Br}$ & $\mathrm{Br}$ & $\mathrm{Br}$ & $\mathrm{Br}$ & $\mathrm{Br}$ & $\mathrm{Br}$ & $\mathrm{Br}$ \\
\hline
\end{tabular}


Table 1 Continued.

\begin{tabular}{llllllllllll}
\hline \multirow{2}{*}{ Characteristics } & \multicolumn{10}{c}{ Isolate codes } \\
\cline { 2 - 5 } & $\mathbf{0 0 9}$ & $\mathbf{0 0 8}$ & $\mathbf{0 1 3}$ & $\mathbf{0 1 7}$ & $\mathbf{0 1 9 a}$ & $\mathbf{0 2 1}$ & $\mathbf{0 0 3}$ & $\mathbf{0 1 9}$ & $\mathbf{0 0 5}$ & $\mathbf{0 0 4}$ & $\mathbf{0 1 2}$ \\
\hline Conidia & & & & & & & & & & & \\
Color & LB & B & LB & LB & LB & DB & DB & LB & B & DB & DB \\
Shape & Ovs & Clc & Ovs & Ovc & Cls & Ovs & Ovs & Ovc & Ovc & Ovc & Ovc \\
VSe & $1-3$ & $3-4$ & $2-5$ & $4-6$ & $3-7$ & $3-5$ & $2-5$ & $2-4$ & $5-7$ & $3-5$ & $1-4$ \\
HSe & $2-3$ & $0-9$ & $0-2$ & $2-8$ & $0-2$ & $1-5$ & $0-2$ & $0-2$ & $0-2$ & $2-4$ & $0-2$ \\
\hline
\end{tabular}

Abbreviations: and Smooth, $\mathrm{G}=\mathrm{Grey}, \mathrm{LG}=$ Light Grey, $\mathrm{OG}=$ Olivereous Grey, $\mathrm{G}=\mathrm{Grey}$, B = Brown, $\mathrm{DG}=$ Dark Grey, DB = Dark Brown, $\mathrm{O}=$ Olivereous, $\mathrm{Dg}=$ Dark green, $\mathrm{g}=$ green, $\mathrm{Cbr}=$ circular zonation with a black rings, $\mathrm{CBr}=$ circular zonation with brown rings, $\mathrm{VSe}=$ Vertical septate, HSe $=$ Horizontal septate, $\mathrm{LB}=$ Light Brown, $\mathrm{B}=$ Brown, $\mathrm{DB}=$ Dark Brown, Ovs = Oval in shape and produced singly, Ovc $=$ Oval in shape and made in chains, $\mathrm{Cls}=\mathrm{Club}$-shape and produced exclusively and Clc $=$ Club-shape and produced in chains, $\mathrm{Sep}=$ Septate, $\mathrm{Br}=$ Branched

\section{Molecular characterization of the isolates}

\section{Agarose gel electrophoresis}

The genomic DNA extracted were positively amplified using ITS 1 (18 base pair) and ITS 4 (20 base pair) primers, and their quality was checked using Agarose gel electrophoresis, all the 11 Alternaria spp isolates showed a positive band of approximately 1600 base pair long (Fig. 4).

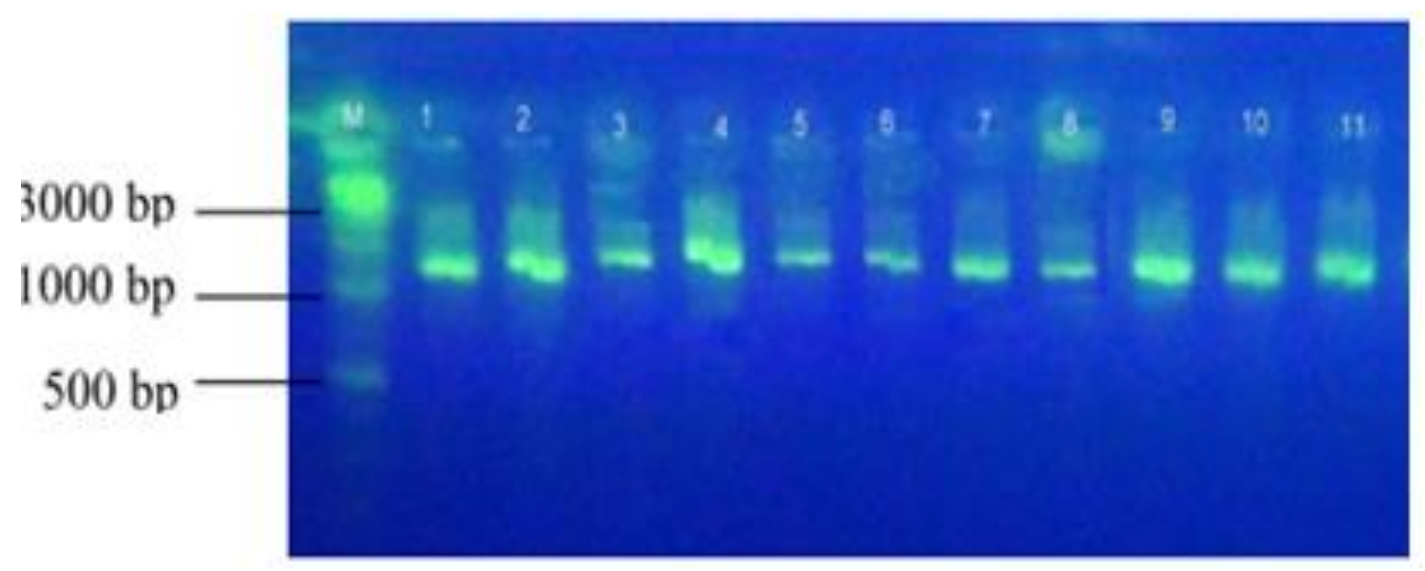

Fig. 4 - Agarose gel electrophoresis of DNA of 11 fungal isolates ran on 1.4\% agarose gel when stained with SYBR green. Line Q-1kb DNA ladder from biolab. Lines 1-11, amplified ITSrDNA of 11 fungal isolates.

\section{Genetic diversity of Alternaria species isolated}

Molecular methods of identification of fungus have been extensively used in taxonomic and phylogenetic studies (Bruns et al. 1991). The technique reveals multiple non-monophyletic genera among the Alternaria spp clusters and Alternaria complex, which do not always correlate to species-group based on morphological characteristics (Woudenberg et al. 2013). The partial sequence analysis of the rDNA gene and internal transcribed spacer regions (ITS1 and ITS4) of the gene, showed a Maximum Likelihood phylogenetic tree which clustered Alternaria spp. isolates into five clusters I, II, III, IV and V (Fig. 5), this could be due to polymorphism occurrence and high variability of different Alternaria spp.

The ITS region of Alternaria isolates showed $99 \%$ other fungi, namely A. brassicicola, A. alternata and A. brassicae (Table 2, Fig. 5). This could possibly be due to the conserved nature of the targeted ITS region located between 16S and 23S rRNA gene that can be used to efficiently determine the identity of numerous fungi species and genera. The analysis concurred with Kusaba 
\& Tsuge (1995) report that Alternaria species which are identified morphologically can be further classified on the basis of variation in ITS of rRNA. Most studies have shown that sufficient variation exists within the ITS regions, which allows for species identification (Iwen et al. 2002).

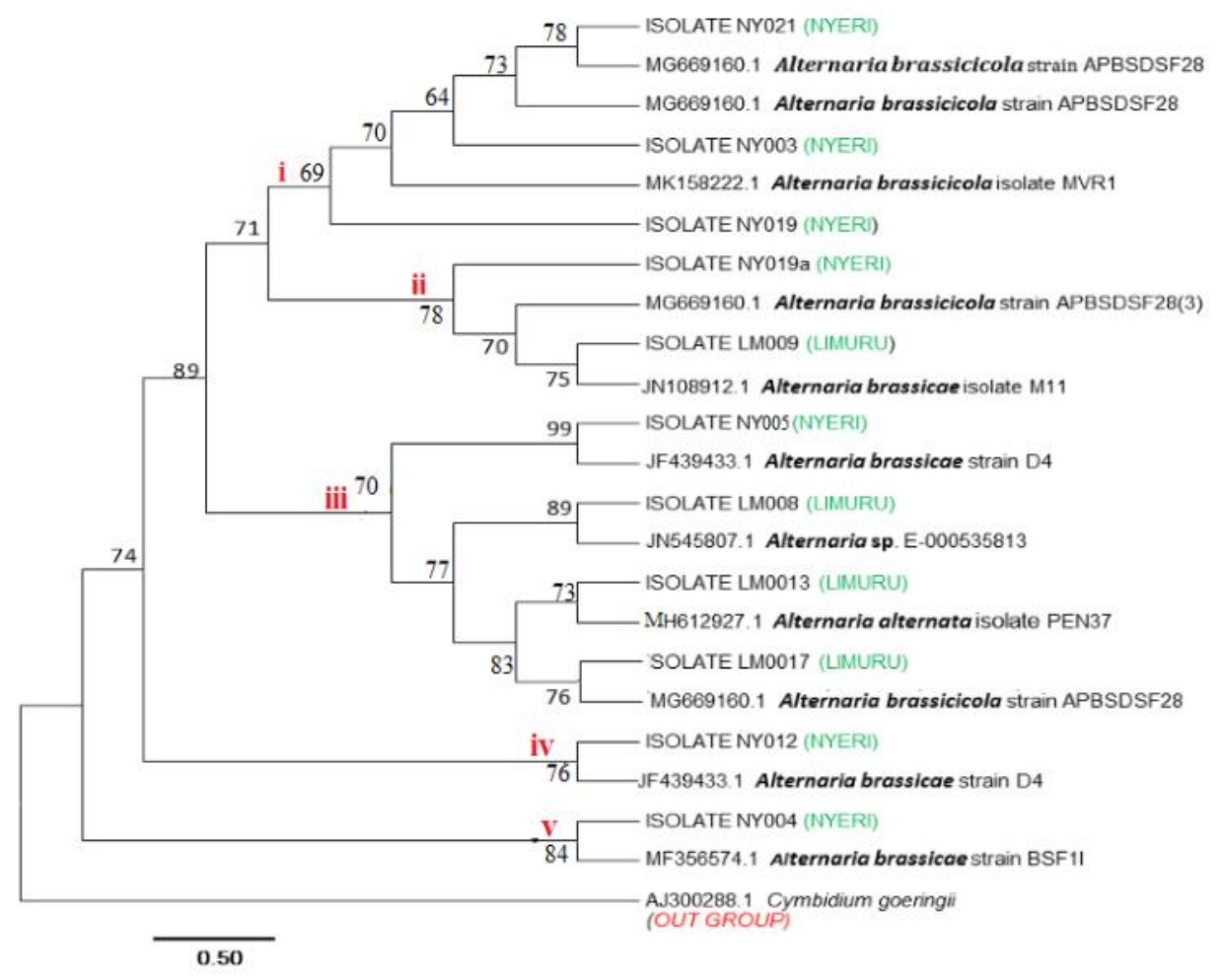

Fig. 5 - Phylogenetic tree of 11 Alternaria spp isolates from cabbage farms at Limuru and Nyeri, Kenya.

The first cluster included isolate NY021, NY003 and NY019 were grouped with Alternaria brassicicola. The second cluster included isolate LM019a, and LM009 was grouped with Alternaria brassicicola reference strain MG669160 and Alternaria brassicae respectively, the third cluster included isolate NY005 was grouped with A. brassicae, isolate LM008 grouped with Alternaria sp, isolate LM013 was grouped with A. alternata and LM017 isolate was grouped with A. brassicicola (MG669160). The fourth cluster consist of only isolate NY012 was grouped with $A$. brassicae (JF439433), while cluster five encompass isolate NY004 grouped with A. brassicae MF356574 (Fig. 5). In the present study, a high degree of genetic variability within the species was observed among the eleven isolates of the genus Alternaria; this variability could be due to extensive dispersal, somatic hybridization, uniform host selection, heterokaryosis and mutation (Pramila et al. 2014). Six isolates of A. brassicicola, four isolates of $A$. brassicae (Berk.) Sacc and one isolate of $A$. alternata were isolated from cabbages leave in Limuru and Nyeri.

The fungi $A$. brassicicola and $A$. brassicacea identified in this study have been reported as the broadest spread and common pathogen of cabbages (Tahere \& Youbert 2015). A. brassicae was found in all Chinese cabbage fields, while A. brassicicola was found in all fields of cruciferous vegetable such as cauliflower, cabbage, broccoli (Michereff et al. 2012). Furthermore, the fungus has been associated with infections of other hosts such as brussels sprouts, bok choy, kale and garden cress (Kohl et al. 2010). The close relatedness of A. brassicicola and A. brassicacea isolates of fungi obtained from cabbage leaves in Nyeri and Limuru, could be due to a possibility that the fungi were transferred through the trade of cabbage in Central Kenya region and they might have originated from the same background. Alternaria brassicicola was identified with high occurrence on cabbages leaves in Nyeri than Limuru farm. Other related species like A. brassicicae was also reported to be a critical necrotrophic pathogen causing Alternaria blight disease on Brassica junce 
(L) in India (Pramila et al. 2014). Alternaria alternata are widely spread and are known to cause infection on a wider range of host such as cabbage, eichhornia, mustard, parthenium, cauliflower, tomato and brinjal, (Meena et al. 2017). A. longipes fungi have been reported to cause leaf spot of potato cultivar in Pakistan and brown spot disease of Tobacco (Yujic et al. 2016).

The phylogenetic relationship tree of the eleven isolates with the know isolates was constructed using MEGA-X (Version 10.0.5) software (Kumar et al. 2018). Phylogenetic tree of evolutionary history was inferred using the Neighbor-Joining method. The evolutionary distances were computed using the Maximum Composite Likelihood method in Kimura 2-parameter model with 1000 bootstrap pairwise and repeat deletion (Tamura et al. 2004).

\section{Sequence data}

The Alternaria pol sequences were deposited at the GenBank under the accession numbers listed in Table 2.

Table 2 The accession No. of isolated Alternaria species.

\begin{tabular}{ll}
\hline Isolate code & Accession No. \\
\hline LM008 & MN636296 \\
LM009 & MN636297 \\
LM013 & MN636298 \\
LM017 & MN636299 \\
NY003 & MN636300 \\
NY004 & MN636301 \\
NY021 & MN636302 \\
NY019a & MN636303 \\
NY019 & MN636304 \\
NY012 & MN636305 \\
NY00 & MN636306 \\
\hline
\end{tabular}

Abbreviations: $\mathrm{LM}=$ Limuru, $\mathrm{NY}=$ Nyeri

\section{Conclusion}

The variation in morphological and molecular characteristics of the eleven isolates observed showed the existence of different strains of Alternaria spp that causes leaf spot disease in cabbage in Limuru and Nyeri, Kenya. Alternaria brassicicola was the most persistent Alternaria spp isolated from infected cabbages leaves. The strains were either grouped with; A. alternata, A. brassicicola or A. brassicae, based on the nucleotide blast done by NCBI site in FASTA(text).

\section{Acknowledgements}

The authors are thankful to Mr Morris Muthini, Mr Gordon Kasera and Mr Kevin Omondi for the assistance they gave us during molecular work of our samples. We also thank the technicians in Microbiology Laboratory at Kenyatta University for their technical support during laboratory experiments. There is no conflict of interest between authors.

\section{References}

Ayongwa GC. 2011 - Understanding the diverse roles of soil organic matter in the cereal - Striga hermonthica interaction. (Doctoral dissertation, Wageningen University, Wageningen, Netherlands).

Bruns TD, White TJ, Taylor JW. 1991 - Fungal molecular systematic. Annual Review of Ecological Systematics 22: 525-564.

Chillali MH, Ladder-Ighili JJ, Guillaumin C, Mohammed B et al. 1998 - Variation in the ITS and IGS regions of ribosomal DNA among the biological species of European Armillaria. Mycol. Res. 102, 533-540. 
Cho HS, Kim BR, Yu SH. 2001 - Taxonomic studies on Alternaria in Korea. Mycobiol 29, $27-42$.

Deep S, Sharma P, Behera N, Chowdappa P. 2014 - Diversity in Indian isolates of Alternaria brassicicola (Schwein) Wiltshire Causing Black Leaf Spot Disease in Cauliflower, Plant Pathol J. 13 (4):232-245.

Ellis MB. 1971 - Dematiaceous Hyphomycetes. Commonwealth Mycological Institute, Kew, Surry, CABI Publishing, Edition-1, 482.

Gontia-mishra I, Tripathi N, Tiwari S. 2014 - A simple and rapid DNA extraction protocol for filamentous fungi efficient for molecular studies. Biotechnology Centre, Jawaharlal Nehru Agricultural University Jabalpur, India. 536-539.

Iwen Pc, Hinrichs SH, Rupp ME. 2002 - Utilization of the internal transcribed spacer regions as molecular targets to detect and identify human fungal pathogens. Med Mycol. 40: 87-09.

Jadhav BM, Perane RR, Kale AA, Pawar NB. 2011 - Morphological, pathological and molecular variability among Alternaria macrospora isolates causing leaf blight of cotton. India Phytopath. 64 (3): 254-257.

Khalse KD, Lal A, Simon S. 2017 - Efficacy of bioagents and plant extracts against the Alternaria leaf spot of cabbage. J. Pharmacogn. Phytochem. 6(4): 1980-1982.

Kimura M. 1980 - A simple method for estimating evolutionary rate of base substitutions through comparative studies of nucleotide sequences. Journal of Molecular Evolution 16: 111-120.

Kohl J, Van Tongeren CAM, Groenenboom-de Haas BH, Van Hoof RA et al. 2010 Epidemiology of dark leaf spot caused by Alternaria brassicicola and A. brassicae in organic seed production of cauliflower. Plant Pathology. 59, 358-367.

Kumar A, Katoch A, Sharma P, Kumar V, Kumar A. 2014 - Pathogenic and genetic variability in Alternaria brassicae infecting rapeseed-mustard and evaluation of resistance sources, India Phytopath. 67(3): 257-262.

Kumar S, Stecher G, Li M, Knyaz C, Tamura K. 2018 - MEGA X: Molecular Evolutionary Genetics Analysis across computing platform. Molecular Biology and Evolution 35: 15471549.

Kusaba M, Tsuge T. 1995 - Phylogeny of Alternaria fungi known to produce host-specific toxins on the basis of variation in internal transcribed spacers of ribosomal DNA. Curr. Genet. 28, 491-498.

Kwasna H, Bateman GL. 2007 - Heteroconium sp.nov.from root of Triticuma estivum in the United Kingdom. Mycology (Vol. 99) 5777-5785.

Lawrence CB, Mitchell TK, Craven KD, Cho Y, Cramer KH. 2008 - At death's door: Alternaria pathogenicity mechanisms. Plant Pathol J. 24(10), 101-111.

MacKinnon SL, Keifer P, William AA. 1999 - Components from the phytotoxic extract of Alternaria brassicicola, a black spot pathogen of canola. Phytochem. 51, 215-221.

Mangala UN, Subbarao M, Ravindrababu R. 2006 - Host range and resistance to Alternaria alternate leaf blight on chilli. J. Mycol. Pl. Pathol 36(1): 84-85.

Meena M, Prasad V, Upadhyay RS. 2017 - Evaluation of Alternaria alternate isolate for metabolite production isolated from different sites of Varanasi, India. Medwin. Vol. 2(1).

Michereff SJ, Noronha MA, Xavier Filha MSM, Câmara MPS, Reis A. 2012 - Survey and prevalence of species causing Alternaria leaf spot on brassica species in Pernambuco. Horticultura Brasileira, 30: 345-348.

Monowara R, Tonu NN, Begum F, Karim MM, Sultana N. 2017 - Morphological and physiological variation among different isolates of Alternaria spp. from Rapeseed-Mustard. International Journal of Environment, Agriculture and Biotechnology, 2(5), 238923.

Muthukumar A, Venkatesh A. 2013 - A new record of leaf blight of ribben plant caused by Alternaria alternate in India, J. on New Biol. Rep. 2(3): 126-138.

Neeraj, Verma S. 2010 - Alternaria diseases of Vegetable Crops and New Approaches for its Control. Asian. Exp. Biol. Sci. 1: 681-692.

Pitt JI, Hocking AD. 1997 - Fungi and Food Spoilage. Sydney: Academic Press. 
Pramila PG, Tasleem M, Taj G, Mal R, Kumar A. 2014 - Morphological, cultural, pathogenic and molecular variability amongst Indian mustard isolates of Alternaria brassicae in Uttarakhand. African Journal of Biotechnology. Vol. 13(3): 441-448.

Pryor BM, Michailides TJ. 2002 - Morphological, Pathogenic and Molecular Characterization of Alternaria isolates associated with Alternaria Late Blight of Pistachio. Phytopath. 92(4): 406-416.

Saha S, Garg R, Venkataravanappa V, Mishra PK et al. 2016 - Molecular and Cultural characterization of Alternaria brassicae Infecting Cauliflower in Uttar Pradesh, India. Biol. Sci. 86: 485.

Samuels GJ, Seifert KA. 1995 - The impact of molecular characters on systematics of filamentous ascomycetes. Ann. Rev. Phytopathol. 33, 37-67.

Sofi TA, Beig MA, Dar Gh H, Ahmad M et al. 2013 - Cultural, morphological, pathogenic and molecular characterization of Alternaria mali associated with Alternaria leaf blotch of Apple, Afr. J. of Biotec. 12(4), 370-381.

Shiro S, Matsuura S, Saiki R, Sigua GC et al. 2013 - Genetic diversity and geographical distribution of indigenous soybean-modulating bradyrhizobia in the United State. Applied and Environmental Microbiology, 79(12): 3610-3618.

Simmons EG. 1995 - Alternaria themes and variation. Mycotaxon 55: 55-163.

Srivastava MP, Chandra S, Tondon RN. 2004 - Post-harvest diseases of some fruits and vegetable. Proc. Nat. Acad. Sci. India. 34: 339-342.

Tahere R, Youbert G. 2015 - The occurrence of Alternaria species on cabbage in Iran. Zemdirbyste-Agriculture. Vol. 102 (2), 343-350.

Tamura K, Nei M, Kumar S. 2004 - Prospects for inferring very large phylogenies by using the neighbor joining method. Vol 101. 11030-11035.

Walker JC. 2010 - Diseases of crucifers. In: Diseases of vegetable crops McGraw Hill Book Co. New York, USA. pp. 150-152.

Woudenberg JHC, Groenewald JZ, Binder M, Crous PW. 2013 - Alternaria redefined. Studies in Mycology 75: 171-212.

Yujic H, Xiao M, Wenting W, Long N. 2016 - Comparative Genomics of pathogens causing brown spot disease of Tobacco: Alternaria longipes and Alternaria alternate. PMID; 11(5). 